\title{
CONTEXTO ESCOLAR E O ENSINO PARA SURDOS: A LIBRAS COMO INSTRUMENTO DE EDUCAÇÃO E DE IDENTIDADE
}

\section{SCHOLL CONTEXT AND TEACHING FOR DEAF: LIIBRAS AS EDUCATION AND IIDENTITY INSTRUMENTS}

\author{
Andrea Guimarães de Carvalho* \\ Renata Rodrigues de Oliveira García**
}

\section{Resumo}

Este artigo discute Libras como instrumento de aprendizagem escolar e de empoderamento da comunidade surda. $\mathrm{O}$ objetivo deste trabalho é trazer reflexões sobre a constituição da cultura e da identidade dos surdos com aquisição tardia de Libras no contexto escolar, verificando ações socioculturais, pedagógicas e interdisciplinares, que ocorrem no processo de ensino e aprendizagem desses alunos. Goldfeld, Quadros e Karnopp, Gesser, Rojo e Perlin, dentre outros autores, que sustentam as discussões teóricas. A metodologia envolveu a investigação dos Projetos Políticos Pedagógicos das escolas investigadas e propostas de ações de letramento envolvendo crianças surdas. Confirmou-se a relação entre a aquisição tardia da língua de sinais e as dificuldades escolares entre os alunos surdos investigados e a necessidade de se usar a Libras como língua de comunicação e interação entre os profissionais e demais alunos dessas escolas.

Palavras-chaves: Libras. Língua e identidade. Inclusão do Surdo. Letramento de surdos.

\section{Introdução}

Reconhecida legalmente no Brasil pela Lei 10.436/02 como uma língua com estrutura linguística própria, a Língua Brasileira de Sinais (Libras) é usada por pessoas surdas para se comunicarem e interagirem no espaço social. Trata-se de uma língua com estrutura própria, cujos aspectos linguísticos constituintes se assemelham aos

\footnotetext{
* Doutoranda em Linguística; Mestre em Educação; Professora do Departamento de Libras e Tradução Faculdade de Letras Universidade Federal de Goiás (UFG), Goiânia, Goiás, Brasil. E-mail: andrea.cenaudio@gmail.com

** Doutoranda em Linguística, UnB; Mestre em Ciências da Saúde da Faculdade de Medicina, UFG; Professora do Departamento de Letras:Libras da Faculdade de Letras, (UFG), Goiânia, Goiás, Brasil. Email: renata.garcia.ufg@gmail.com
} 
encontrados nas demais línguas. É uma língua que apresenta aspectos fonológicos, morfológicos, sintáticos e semântico-pragmáticos próprios, assemelhando-se, portanto, às línguas orais, conhecidas por serem de modalidade oral-auditiva, enquanto as de sinais possuem modalidade espaço-visual (QUADROS e KARNOPP, 2004).

Essas informações sobre semelhanças e diferenças entre línguas, principalmente no que se refere à estrutura linguística, trazem reflexões importantes quando ensinadas em contexto escolar. No caso de alunos surdos, expostos ao ensino da língua portuguesa escrita, língua de instrução utilizada na grande maioria das escolas públicas no Brasil, nota-se a persistente evidência de seus fracassos na aprendizagem escolar, uma vez que sua língua natural é a Libras, e não a língua portuguesa.

Além disso, se levanta também a importância da mútua relação entre o aprendizado de uma língua, a construção de identidade e os aspectos socioculturais envolvidos nesse processo, pois esses elementos estão intrinsicamente articulados durante todo o processo escolar e, até mesmo, na formação e desenvolvimento de um indivíduo (GESSER, 2012).

Nesse contexto, vários questionamentos são levantados sobre a eficácia da educação dos surdos nas escolas públicas, na atualidade. Como promover um ensino escolar de qualidade quando o aluno surdo ainda não adquiriu nenhuma língua que pudesse construir uma identidade? No caso da ausência da Libras, língua natural ou primeira língua (L1) dos surdos, porque a escola ainda persiste no ensino do português escrito a esses alunos, uma vez que a Libras será a língua de referência para aprendizagem do português (L2), segunda língua para os surdos? Como os surdos podem aprender uma L2 na ausência de uma L1? Que ações linguísticas e pedagógicas, seriam efetivas para reverter ou amenizar esses problemas?

A partir dessas questões, é possível enumerar algumas das barreiras escolares para a educação dos surdos, tais como: crianças surdas sem uma língua natural (Libras); sem uma identidade definida; dificuldades na compreensão normativa e funcional da estrutura linguística do português como L2.

Dessa forma, os objetivos da pesquisa foram desenvolvidos em duas etapas: 1) o entendimento de como ocorre a constituição das culturas e identidades de surdos com aquisição tardia de Libras no contexto escolar e como a escola se organiza promovendo 
essa constituição, desencadeando, então a promoção do ensino-aprendizagem do aluno surdo; 2) a proposição de ações socioculturais (dentro e fora da escola) e pedagógicas, interdisciplinares, que contribuam para a superação, ou para amenizar barreiras relacionadas com as dificuldades de aprendizagem dos surdos no contexto escolar, a falta de aquisição de sua língua natural e o desenvolvimento de sua identidade surda.

\section{Surdez, libras e o sujeito surdo}

Conforme o Decreto $\mathrm{n}^{\circ} 5.626$, de 22 de dezembro de 2005, Art. $2^{\circ}$, entende-se por pessoa surda aquela que, por ter perda auditiva, compreende e interage com o mundo por meio de experiências visuais, manifestando sua cultura principalmente pelo uso da Libras. Segundo o parágrafo único da Lei №10.436, de 24 de abril de 2002:

\footnotetext{
Entende-se como Língua Brasileira de Sinais - Libras a forma de comunicação e expressão, em que o sistema linguístico de natureza visualmotora, com estrutura gramatical própria, constitui um sistema linguístico de transmissão de ideias e fatos, oriundos de comunidades de pessoas surdas do Brasil (BRASIL, 2002).
}

No Brasil, comunidades de pessoas surdas vêm lutando, por décadas, pelo reconhecimento legal da Libras e por um espaço em meio à sociedade majoritária ouvinte. O reconhecimento legal da Libras desencadeou uma série de ações afirmativas na área da educação e da saúde, abrindo oportunidades tanto para a disseminação dessa língua no âmbito nacional, como também para uma nova visão sociocultural da surdez e do sujeito surdo, assim como novas reformulações teórico-práticas de língua na sociedade como um todo.

Essas lutas e conquistas demarcaram historicamente um olhar diferenciado sobre a comunidade surda. Segundo Silva (2003, p. 58), a busca pela "construção da identidade desses surdos na sociedade alavanca de paradigma da deficiência para o de minoria linguística e cultural". De acordo com Perlin (1998, p. 20), "ser surdo é, antes de tudo, uma experiência num mundo visual". Strobel (2013, p. 45) observa que "os sujeitos surdos, com a sua ausência de audição e do som, percebem o mundo através de seus olhos e de tudo o que ocorre ao redor". Os estudos de Pereira (2011, p.55) corroboram essas colocações ao esclarecerem que "a língua de sinais permite aos surdos se identificarem como sujeitos capazes [...], cuja característica principal é ser visual”. 
Essa nova visão linguística e social, permite ao surdo expor o seu jeito visual de ser, com características que atendem as suas necessidades, tais como: o uso de uma língua natural que norteie uma interação social, uma comunicação significativa e autonomia nas diferentes formas de adquirir conhecimentos e de atuarem na sociedade.

Com isso, se reforça a ideia de que o surdo tem sua língua natural ${ }^{1}$, uma língua de sinais, que no caso do Brasil é a Libras. Uma língua que não só lhe permite desenvolver habilidades cognitivas, linguísticas e socioculturais ${ }^{2}$, como constituir sua identidade e cidadania.

\section{Letramento de surdos no contexto escolar}

Nesta seção, busca-se destacar a importância da Libras, que conduz o surdo à construção de sua identidade e à reflexão sobre questões que levem a repensar sobre as propostas de letramento para surdos, as propostas curriculares atuais e as políticas educacionais e linguísticas envolvidas nesse processo. A primeira dessas questões: no contexto escolar, quais seriam as consequências da falta da língua de sinais para o surdo? A segunda questão expõe os desafios de como proceder o letramento de surdos sem uma base linguística mínima que os capacite a construir discursos significativos ou formar conceitos capazes de orientá-lo na interpretação de fatos cotidianos.

O conceito de letramento, considerado neste trabalho, pode ser entendido como o "conjunto de práticas de comunicação social relacionadas ao uso de materiais escritos, e que envolvem ações de natureza não só física, mental e linguístico-discursivas como também social e político-ideológico" (SIGNORINI, 2001, p.8-9). Observamos que esse tema, anteriormente discutido por Kleiman (1995) e Rojo (2001), apresenta as práticas de letramento como formas plurais, determinadas social, histórico e culturalmente, que podem ser compreendidas como um processo contínuo entre práticas orais, sinalizadas e escritas, extrapolando, assim, o universo da escrita. Tal concepção está vinculada à presença de "eventos de letramento", descritos por Kleiman (1995) como situações em que a escrita se torna fundamental para a construção de sentidos no discurso oral da criança, antes mesmo de ser exposta à aprendizagem formal da escrita na escola.

Rojo (2001, p.56) salienta ainda que o reconhecimento de processos e práticas diferenciadas em ambientes como a família, a igreja e a escola, dentre outros, chamados 
de "agências de letramento", devem ser levados em consideração nos processos de ensino-aprendizagem. Isso demarca o fato de o letramento estar vinculado a múltiplas práticas, num processo contínuo de desenvolvimento de linguagem, no qual oralidade, sinalização e escrita se imbricam nas interações verbais.

Ser letrado é participar ativamente de práticas discursivas letradas (orais, sinalizadas e escritas), a partir dos diversos materiais de circulação social propiciados pelas "agências de letramento". Dessa forma, deve-se pensar nas estratégias de ensinoaprendizagem escolar articuladas às experiências socioculturais vivenciadas pelas crianças em seu cotidiano, dentro e fora da unidade escolar. Essas experiências são os recursos materiais e visuais que contemplarão os argumentos discursivos que darão sentido às suas criações orais e escritas.

O que se observa na escola, em geral, são as práticas de letramento limitadas ao ensino de regras gramaticais e à concepção estrutural dos gêneros discursivos, desvinculadas do contexto social. Essas práticas em nada se assemelham aos gêneros em circulação nas práticas sociais do cotidiano dessas crianças. Principalmente em relação à criança surda, cujas vivências linguísticas, constituídas através da língua de sinais, no caso a Libras, se diferenciam daquelas que envolvem as crianças ouvintes, com foco na língua oral portuguesa.

Ainda sobre a vivência linguística experimentada pelas crianças surdas, nota-se que, na escola, essa vivência e o uso da Libras não se estendem de forma equivalente a todas elas. Nas escolas com propostas inclusivas encontramos crianças surdas com diferentes níveis de domínios domínio do uso e do conhecimento da Libras, levando a fracassos contínuos dessas crianças em ambientesescolares.

\section{Metodologia}

A pesquisa, de cunho qualitativo, envolveu a investigação de sete escolas, sendo seis escolas públicas inclusivas no município de Senador Canedo e uma escola estadual que funcionava na Associação de Surdos de Goiânia (ASG). No total foram 19 alunos surdos sendo 10 alunos surdos da escola estadual, que funcionava no período noturno, na ASG entre 15 e 16 anos e, nas escolas municipais de Senador Canedo foram 
9 alunos em escolas municipais de Senador Canedo 7 e 16 anos, matriculados em diferentes níveis escolares.

Dos 9 alunos surdos das escolas municipais, 3 usavam Aparelho de Amplificação Sonora (AASI). Do total desses alunos, somente 2 conseguiam se comunicar fluentemente em Libras. Os demais tentavam se comunicar com os ouvintes através da leitura labial e por meio de reprodução oral mal articulada. Dos 10 alunos da ASG, nenhum usava AASI e 6 se comunicavam em Libras, enquanto os 4 restantes procuravam se comunicar por meio de leitura labial e por reprodução oral mal articulada.

Os instrumentos utilizados na pesquisa foram: estudo e análise documental do Projeto Político Pedagógico das escolas investigadas; verificação da existência, ou não, de projetos de letramento para os alunos surdos; observação das aulas de alguns professores como os de português e história. No caso das escolas municipais, também foram observados alguns atendimentos do professor responsável pelo Atendimento Educacional Especilaizado (AEE). A pesquisa teve a duração de 6 meses consecutivos e pode ser dividida, cronologicamente, em três etapas:

No primeiro mês foram verificados e analisados os Projetos Políticos Pedagógicos das escolas-campo e os projetos escolares que tratavam de ações pedagógicas de letramento. Foram observadas as estratégias de ensino dos professores regentes de classe e da sala de Atendimento Educacional Especializado (AEE), no ambiente escolar como um todo (sala de aula, na sala de AEE e nos espaços de recreações e de dinâmicas coletivas) e nas programações socioculturais envolvendo a comunidade em torno da escola.

No segundo mês, a partir dos resultados obtidos, foram planejadas ações e estratégias socioculturais e pedagógicas interdisciplinares junto aos profissionais da educação, envolvidos diretamente com os alunos surdos. Do terceiro ao sexto mês, as ações anteriormente planejadas foram aplicadas nas escolas. 


\section{Resultados e discussões}

Das sete escolas municipais de Senador Canedo investigadas, em seis foram observados alunos surdos com aquisição tardia da Libras e de suas identidades como surdos. Nessas escolas, confirmou-se a inclusão limitada dos surdos, com atividades não adapatadas e o uso inadequado dos intérpretes de Libras. Além disso, os alunos surdos não haviam se apropriado de sua língua natural, pois a maioria dos pais, que era ouvinte, não havia utilizado a Libras desde o nascimento de seus filhos surdos. Além disso, como não reconheciam a cultura surda, os filhos não tinham uma identidade surda definida.

Nessas escolas, destaca-se o fato de cada aluno surdo ser único, e não ter outro colega na mesma condição. Para esses alunos, a única referência de uso da Libras era a dos intérpretes escolares. Nas escolas municipais pesquisadas, confirmaram-se as dificuldades desses alunos na aprendizagem dos conteúdos escolares e seus fracassos contínuos, principalmente, na compreensão da estrutura linguística da Língua Portuguesa como segunda língua. Essas dificuldades se agravaram devido à não aquisição de uma primeira língua, no caso da Libras, para o desenvolvimento cognitivo e de linguagem desses alunos. Goldfeld (1997, p. 44) afirma que "a criança surda, ao sofrer atraso de linguagem, mesmo que aprenda uma língua tardiamente terão sempre como consequência deste atraso problemas emocionais, sociais e cognitivos".

No grupo de alunos surdos que frequentava a ASG, notou-se uma realidade distinta. Nesta escola estadual era comum o uso da Libras como língua de interação entre os alunos que frequentavam a instituição, tanto no recreio como nos intervalos entre as aulas. Esse uso da Libras pela maioria dos alunos permitia maior troca de experiências e aquisição natural para alunos surdos 'iniciantes', que ainda não dominavam a Libras. Essa experiência lhes dava o sentimento de pertencimento e participação social, dentro e fora da sala de aula, colaborando para a constituição de suas identidades.

Na ASG, apesar de a maioria dos professores não utilizarem a Libras como língua de instrução e das limitações da escola frente aos recursos visuais, notou-se um esforço maior de alguns professores como de física, química, geografia e de artística no uso de metodologias visuais diferenciadas, para atender às necessidades dos alunos 
surdos, por meio de recursos visuais, como uso de tablets ou celulares, desenhos e imagens em cartazes, mais frequentes nas salas de aula.

Nas escolas municipais de Senador Canedo, o único recurso era limitado à presença do intérprete de Libras. Não ocorria o uso de outros meios tecnológicos ou visuais para suprir a necessidade dos alunos surdos para complementar melhor entendimento visual dos conteúdos escolares, tal como cocorria na ASG, escola de âmbito estadual, onde há mais surdos do que nas escolas municipais de Senador Canedo.

Sobre os Projetos de Letramento e os Projetos Político Pedagógicos das escolas, não havia nada em especial envolvendo os alunos surdos e nem propostas de ações futuras. A partir desses resultados, duas ações foram planejadas e propostas junto aos professores das disciplinas observadas, professores do AEE e coordenadores pedagógicos das instituições:

a) uma ação envolvendo um encontro semanal entre os alunos surdos e um professor surdo, com o objetivo de ensinar Libras, usando gêneros textuais e temas atuais passados em TV, facebook e istagran, permitindo trabalhar o desenvolvimento da identidade e cultura surda, agregada à aquisição da Libras L1, tendo o professor surdo como modelo;

b) outra ação propunha aulas no AEE que utilizavam temas atuais, a partir dos gêneros textuais, com auxílio do intérprete de Libras e reforço de uma linguagem visual, imagética (filmes, figuras, livros ilustrados), contextualizadas, com foco na abordagem discursiva.

Logo de início, na execução conjunta dessas ações, percebeu-se maior desenvolvimento dos alunos surdos, tanto na desenvoltura, como no uso adequado da Libras em contextos discursivos distintos. Nesses encontros, o professor surdo procurava resgatar os temas de cada aula, através de gravuras, desenhos dos alunos surdos, primeiramente em Libras e, depois, em português escrito. Os alunos criavam seus textos e apresentavam aos demais. Aos poucos surdos identificavam palavras e frases apontadas pelo professor surdo, fazendo associações com os textos anteriormente apresentados em Libras. Isso promovia uma aprendizagem significativa e contextualizadar. 
Com essas propostas, usando uma abordagem discursiva, cujos métodos didático-pedagógicos respeitaram as experiências visuais e linguísticas da pessoa surda, amenizaram-se as dificuldades escolares desses alunos. Foram também motivados a participarem mais das aulas e dos encontros entre surdos para troca de experiências socioculturais.

Os resultados dessa pesquisa sugerem que o ensino bilíngue para surdos é mais vantajoso para o desenvolvimento global dos alunos surdos. Salienta-se, também, a necessidade de demonstrar aos familiares desses alunos a importância de aprenderem a Libras para se comunicarem adequadamente com seus filhos. A escola deve estimular a participação da família, desenvolvendo discussões temáticas para os alunos surdos e seus familiares, intermediadas por psicólogos, assistentes sociais, dentre outros.

\section{Considerações finais}

Com esta pesquisa, foi possível identificar que as crianças surdas têm dificuldades na comunicação em Libras com seus familiares ouvintes e apresentam atraso da aquisição da Libras dentro e fora do ambiente escolar. Em algumas crianças, foram constatados atrasos no desenvolvimento de linguagem, em habilidades de memória, capacidade de categorização e discriminação visual, essenciais para o desenvolvimento global de uma criança. Isso ocorreu porque os alunos não tiveram contato, na tenra infância, com uma comunidade usuária de Libras. Situação diferente da identificada entre os alunos surdos da ASG.

O uso e o ensino da Libras no ambiente escolar e o contato com adultos surdos, remetem a um comportamento singular, que demarca a cultura surda, de grande importância na construção de identidade do aluno surdo e na motivação para o aprendizado de uma língua, no caso a Libras.

O ensino por meio da Libras apresentou vantagens, quando bem utilizado junto a outras ações interdisciplinares no ambiente educacional. As ações colaborativas de todos os profissionais envolvidos no processo de ensino-aprendizagem dos alunos surdos se faz necessária, tal como se mostrou na criação de aulas e atividades interdisciplinares envolvendo os gêneros textuais e melhores usos de recursos visuais. 
É necessário refletir sobre ações que envolvam a comunidade escolar, incluindo a família, na promoção da Libras e na inclusão social do surdo. Assim, ao se pensar em ensino escolar e letramento para alunos surdos, as ações, projetos e o planejamento escolar devem ser repensados. Além disso, as condições e experiências linguísticas vividas e trazidas por esses alunos para a sala de aula, devem ser levadas em conta. A partir delas, será possível traçar novas perspectivas e práticas pedagógicas para que se possa proporcionar ao aluno surdo um letramento significativo, sem ignorar sua identidade e favorecendo à constituição de sua cidadania.

\begin{abstract}
This article discusses Libras as an instrument for school learning and empowerment of the deaf community. The objective of this paper is to bring reflections on the constitution of the culture and identity of deaf people with late acquisition of Libras in the school context, verifying sociocultural, pedagogical and interdisciplinary actions that occur in the teaching and learning process of these students. Goldfeld, Quadros and Karnopp, Gesser, Rojo and Perlin, among other authors, support the theoretical discussions. The Projetos Politicos Pedagógicos of the investigated schools were studied, and literacy actions proposed for deaf children. It was also confirmed the relationship between late acquisition of sign language and school difficulties among the deaf students investigated, as well as the need to use Libras as a language of communication and interaction between professionals and other students of these schools.
\end{abstract}

Keywords: Libras. Language and identity. Deaf inclusion. Deaf literacy.

\title{
Referências
}

BRASIL. LEI No 10.098, DE 19 DE DEZEMBRO DE 2000. Estabelece normas gerais e critérios básicos para a promoção da acessibilidade das pessoas portadoras de deficiência ou com mobilidade reduzida, e dá outras providências. Disponível em: <http://www .planalto.gov.br/ccivil_03/leis/L10098.htm>. Acesso em: mar. 2019.

GESSER, A. O ouvinte e a surdez: sobre ensinar e aprender a Libras. I. ed. São Paulo: Parábola Editorial, 2012. 200 p.

GOLDFELD, M. A criança surda: linguagem e cognição numa perspectiva sóciointeracionista. São Paulo: Plexos, 1997.

KLEIMAN, A. Modelos de letramento e as práticas de alfabetização na escola. In: Os significados do letramento: uma nova perspectiva sobre a prática social da escrita. Campinas, SP: Mercado das Letras, 1995. 
PERLIN, G.T.T. Histórias de vida surda: identidades em questão. Dissertação (Mestrado) - Universidade Federal do Rio Grande do Sul, Porto Alegre. Publicada em 1998. Disponível em: <http://www.unisc.br/portal/upload/com_arquivo/historias _de_vida_surda_identidades_em_questao.pdf >. Acesso em: mar. 2019.

PEREIRA, M.C.C. Libras: Conhecimento além dos sinais. In: CHOI, D.; VIEIRA M.I.; GASPAR, P.; NAKASATO, R. (Org.). São Paulo: Pearson Prentice Hall, 2011.

QUADROS, R. M. Educação de surdos: a aquisição da linguagem. 2 ed. Porto Alegre: Artmed, 2008.

QUADROS, R. M. e KARNOPP, L. B. Língua Brasileira de Sinais. Estudos Linguísticos. Porto Alegre: Artmed, 2004.

ROJO, R. Letramento escolar, oralidade e escrita em sala de aula: diferentes modalidades ou gêneros do discurso? In: SIGNORINI, I.(org.). Investigando a relação oral/escrita e as teorias do letramento. Campinas: Mercado das Letras, 2001.

SANTA CATARINA (Estado). Política de educação Especial do Estado de Santa Catarina: Programa Pedagógico. Secretaria de Estado da Educação. São José, SC: FCEE, 2006.

SIGNORINI, I. Investigando a relação entre oral/escrito e as teorias de letramento. Campinas, SP: Mercado das Letras, 2001.

SILVA, I.R.; KAUCHAKJE, S.; GESUELI, Z.M.. Cidadania, surdez e linguagem: Desafios e realidades. São Paulo: Plexus Editora, 2003.

STROBEL, K. As imagens do outro sobre a cultura surda. 3. Ed. Florianópolis: Ed. Da UFSC, 2008.

\section{Notas}

\footnotetext{
${ }^{1}$ A Língua Brasileira de Sinais (LIBRAS) é utilizada pelos surdos como meio de comunicação e interação: social, politica, pedagógica e cultural.

${ }^{2} \mathrm{Na}$ comunidade surda há características específicas que envolvem a "cultura surda", utilizadas por membros surdos ou ouvintes utentes da LIBRAS como meio de comunicação e interação social. Sobre esse assunto ler Strobel (2008) As imagens do outro sobre a cultura surda.
}

Submetido em 26 de maio de 2019.

Aceito em 14 de novembro de 2019.

Publicado em 02 de novembro de 2019. 